Canadian

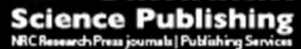

Canadian Journal of Forest Research Revue canadienne de recherche forestière

\title{
Post-stratified change estimation for large-area forest biomass using repeated ALS strip sampling
}

\begin{tabular}{|r|l|}
\hline Journal: & Canadian Journal of Forest Research \\
\hline Manuscript ID & cjfr-2017-0031.R2 \\
\hline Manuscript Type: & Article \\
\hline Date Submitted by the Author: & 08-Mar-2017 \\
\hline Complete List of Authors: & $\begin{array}{l}\text { Strimbu, Victor; Norwegian University of Life Sciences, Department of } \\
\text { Ecology and Natural Resource Management } \\
\text { Ene, Liviu; Norwegian University of Life Sciences, Department of Ecology } \\
\text { and Natural Resource Management } \\
\text { Gobakken, Terje; Norwegian University of Life Sciences, Department of } \\
\text { Ecology and Natural Resource Management } \\
\text { Gregoire, Timothy; Yale University } \\
\text { Astrup, Rasmus; Norwegian Institute of Bioeconomy Research } \\
\text { Næsset, Erik; Norwegian University of Life Sciences, Department of } \\
\text { Ecology and Natural Resource Management }\end{array}$ \\
\hline Keyword: & $\begin{array}{l}\text { airborne laser scanning, above ground biomass, change estimation, } \\
\text { stratified estimation, parametric bootstrapping }\end{array}$ \\
\hline
\end{tabular}




\section{Post-stratified change estimation for large-area 2 forest biomass using repeated ALS strip sampling

4 Victor Felix Strîmbu (corresponding)

5 Department of Ecology and Natural Resource Management, Norwegian University of Life Sciences, P.O.

6 Box 5003, NO-1432 Ås, Norway

7 victor.strimbu@nmbu.no

8 Tel. +4797044678

$9 \quad$ Liviu Theodor Ene

10 Department of Ecology and Natural Resource Management, Norwegian University of Life Sciences, P.O.

11 Box 5003, NO-1432 Ås, Norway

12 liviu.ene@nmbu.no

13 Terje Gobakken

14 Department of Ecology and Natural Resource Management, Norwegian University of Life Sciences, P.O.

15 Box 5003, NO-1432 Ås, Norway

16 terje.gobakken@nmbu.no

17 Timothy G. Gregoire

18 School of Forestry and Environmental Studies, Yale University, New Haven, CT 06511-2104, USA

19 timothy.gregoire@yale.edu

20 Rasmus Astrup

21 Norwegian Institute of Bioeconomy Research, P.O. Box 115, NO-1431 Ås, Norway

22 rasmus.astrup@nibio.no

23 Erik Næsset

24 Department of Ecology and Natural Resource Management, Norwegian University of Life Sciences, P.O.

25 Box 5003, NO-1432 Ås, Norway

26 erik.naesset@nmbu.no

27 


\section{Abstract}

Post-stratified model-assisted (MA) and hybrid (HY) estimators are used with repeated airborne laser scanning (ALS) strip sampling and national forest inventory field data for stratum-wise and overall estimation of above ground biomass (AGB) stock and change. The study area covered the southern portion of the Hedmark County in Norway. Both MA and HY estimation substantially reduced the uncertainty in AGB change when compared to estimation using the field survey only. Relative

34 efficiencies (relative variance) of $4.15(\mathrm{MA})$ and $3.36(\mathrm{HY})$ for overall estimates were found. The results

35 suggest the MA estimator for single-time estimation and the HY as more appropriate for change

36 estimation by cover class. With the HY estimator, a nested post-stratification scheme is demonstrated,

37 combining cover classes with change classes, which enables detailed reporting for change according to

38 cause within each cover class, and has the potential to improve the estimation precision. Finally,

39 parametric bootstrapping is demonstrated as an empirical alternative to estimate the model-error

40 component in the HY estimator. The model-error estimated with parametric bootstrapping converged to

41 the analytically determined value of the HY estimator within 1000 bootstrap samples.

42 Key words: airborne laser scanning, above ground biomass, change estimation, stratified estimation, 43 parametric bootstrapping 


\section{INTRODUCTION}

46

47

The international community, through various organizations, frameworks and formal resolutions (e.g. Intergovernmental Panel on Climate Change (IPCC), United Nations Programme on Reducing Emissions from Deforestation and Forest Degradation (UN-REDD and REDD+), Paris Agreement), becomes increasingly coherent and articulated when expressing the need to quantify and monitor the forest carbon stocks and carbon stock change. As the world's forests have been identified as a major carbon sink (Pan et al. 2011), the scientific community feels mandated to investigate and propose methods to estimate large-scale forest biomass and biomass change, and do so efficiently, mindful of both cost and uncertainty (IPCC 2006).

This sets us in the domain of large-area forest survey (i.e., regional or national scale), where the role of remotely sensed data is resolute. Airborne laser scanning (ALS) has been an excellent source of auxiliary data in forest surveys, with great predictive power for forest attributes such as above ground biomass (AGB) or wood volume. As the acquisition cost for such data remains relatively high, ALS sampling has been proposed as a feasible alternative for large-area AGB estimation (Andersen et al. 2011; Gobakken et al. 2012; Gregoire et al. 2011; Næsset 2005; Næsset et al. 2013b; Saarela et al. 2015; Ståhl et al. 2011). Typically, the ALS survey follows a strip sampling design, which together with field plot data are used to estimate AGB. A certain amount of experience has been gained in estimating forest parameters using ALS strip sampling, and while there have been several studies that use repeated wall-to-wall ALS surveys to estimate the change in these parameters (Bollandsås et al. 2013; Magnussen et al. 2015; McRoberts et al. 2015; Næsset et al. 2013a; Skowronski et al. 2014), large-area change estimation via ALS strip sampling is of more recent opportunity. In fact, change estimation following repeated ALS strip survey has only been tackled in Ene et al. (2017) where change in AGB was estimated in miombo woodlands in a district in Tanzania. With respect to estimation following ALS strip sampling, two distinct 
68 approaches have been proposed: two-stage model-assisted (MA) (Gregoire et al. 2011) and two-phase

69 hybrid (HY) (Ståhl et al. 2011). While the MA estimation relies exclusively on design-based inference, the

70 HY estimation, a notion introduced by Corona et al. (2014), combines design-based inference with

71 model-based inference. For a discussion on the difference between design-based and model-based

72 inferences, see Gregoire (1998). Ståhl et al. (2016) gives an overview on how design-based and model-

73 based inferences can be used separately or combined in large-area forest surveys.

74 The main objective of the present study was to estimate forest biomass and biomass change over a

75 period of five years in a large area spanning the southern portion of Hedmark County, Norway. With

76 respect to this objective, it counterparts Ene et al. (2017), using a sample of ALS and NFI plots to

77 estimate change, this time in a boreal forest. Here, more specific objectives were: (i) to introduce post-

78 stratified MA and HY change estimation, (ii) test a nested stratification scheme, by cover class and

79 change class, and (iii) to demonstrate parametric bootstrapping as an empirical alternative to estimate

80 the model-error component. Demonstrated on HY estimation, the nested stratification scheme aimed to

81 increase the estimation precision as well as to enable and demonstrate detailed reporting of forest

82 biomass change according to cause of change, in each cover class. Parametric bootstrapping entails

83 sampling from the multivariate distribution of the model parameters. The role of this exercise was

84 twofold. First, it serves as mutual validation with the analytically determined model-error component, as

85 both methods are yet to be established in the literature (i.e., at least for two-phase post-stratified

86 change estimation). In addition, parametric bootstrapping could be the feasible alternative in situations

87 where the model-error component becomes too complex for analytical determination, due to either

88 design complexity (i.e., multistage, stratification) or error propagation from multiple modeling steps. 


\section{MATERIALS AND METHOdS}

\subsection{Materials}

The study area is the southern portion of Hedmark County in Norway (Fig.1), covering approximately one third of the region $\left(9758 \mathrm{~km}^{2}\right.$ out of $\left.27390 \mathrm{~km}^{2}\right)$. Restricting the study to a fraction of the region was constrained by the extent of the repeated ALS acquisition campaign. The area is considered to have some of the most productive forests in Norway, with dominant tree species typical to the boreal forests of the Nordic region: Norway spruce (Picea abies (L.) Karst.), Scots pine (Pinus sylvestris L.) as well as a minor proportion of white birch (Betula pubescens Ehrh.)

The Norwegian National Forest Inventory (NFI) provided the field data. The NFI survey (Tomppo et al. 2010) consists in $250 \mathrm{~m}^{2}$ circular plots distributed systematically on a $3 \times 3 \mathrm{~km}$ grid, with $20 \%$ revisited every year according to a Latin square design with blocks of $45 \times 45 \mathrm{~km}$. The AGB for individual trees was predicted with allometric models (Marklund 1988), aggregated at the plot level, and scaled to perhectare values.

The years of reference for this study are 2006 and 2011. Field plots measured under the ninth inventory cycle of the NFI in 2005, 2006, and 2007 constitute the observations for the first point in time (2006), and the same plots revisited five years later under the tenth inventory cycle in 2010, 2011, and 2012 are ascribed to the second point in time (2011). For the entire area, 322 plots were overlapped by the ALS strip survey, six of which were discarded on grounds of inconsistency between ALS data and field measurements. These inconsistencies were, in some cases, caused by forest that suffered changes between the field survey and ALS acquisition in either 2006 or 2011. The mean AGB of the remaining 316 plots was $60.8 \mathrm{Mg} / \mathrm{ha} \mathrm{(2006)}$ and $67.1 \mathrm{Mg} / \mathrm{ha} \mathrm{(2011).} \mathrm{For} \mathrm{modeling,} \mathrm{only} \mathrm{observations} \mathrm{with} \mathrm{nonzero}$ AGB on both 2006 and 2011 were used (234 plots). This filtering was necessary as the models were 
111 fitted on log transformed variables, and with a pair-wise correlation structure (i.e. compound symmetry) 112 that requires observations from both times (2006 and 2011).

113 The ALS survey consists in two sets of $24 \mathrm{E}-\mathrm{W}$ flight lines spaced $6 \mathrm{~km}$ apart and with a swath width of 114 approximately $500 \mathrm{~m}$ (Fig. 1). The survey was conducted in three acquisition campaigns (see Table 1), 115 with the same flight lines being overflown a second time. The ALS data were tessellated with a grid cell 116 size of $15.81 \mathrm{~m}$, matching the area of an NFI plot, and portions of the strips that did not spatially overlap 117 for the 2006 and 2011 acquisitions were discarded, assuring a one-to-one correspondence between 1182006 and 2011 at the grid cell level.

119 Two different types of stratification were used: by cover class and change class. Cover class stratification 120 was done for the entire area, based on land use maps and satellite imagery as described in (Gobakken et 121 al. 2012). Here we use five cover classes (proportion in parenthesis): nonproductive/non-forest (24\%), 122 young forest (31\%), low productive forest (13\%), medium productive forest (21\%), and high productive 123 forest (12\%). The nonproductive/non-forest cover class aggregates the following categories:

124 nonproductive forest, mountain forest (>850 $\mathrm{m}$ altitude), developed areas, and open water.

125 Stratification by change class was done at the level of the ALS strip sample following a rule-based 126 classification. Four change classes were defined as follows (proportion in parentheses, followed by the 127 rule):

- $\quad$ unchanged forest (84.5\%), laser echoes above $1.3 \mathrm{~m}$ on both occasions (2006 and 2011)

129 - clear-felled forest (1.6\%), laser echoes above $1.3 \mathrm{~m}$ only on the first occasion (2006)

$130 \quad-\quad$ regenerated forest (1.8\%), laser echoes above $1.3 \mathrm{~m}$ only on the second occasion (2011)

131 - unchanged non-forest (12.1\%), no laser echoes above $1.3 \mathrm{~m}$ on either occasion (2006 or 2011). 


\section{$132 \quad 2.2$ MODELS}

133 The relation between ALS data and field estimated AGB was modeled via height and density metrics

134 (Gobakken et al. 2012). The height metrics include 10 height percentiles $\left(h_{00}, h_{10}, h_{20}, \ldots, h_{90}\right)$,

135 maximum height $\left(h_{\max }\right)$, and the coefficient of variation $\left(h_{c v}\right)$. Density metrics $\left(d_{0}, d_{1}, \ldots, d_{9}\right)$ for 10

136 equal height levels between $1.3 \mathrm{~m}$ and the $95^{\text {th }}$ height percentile, were calculated as the proportion of

137 laser echoes above the respective height to the total number of echoes (including those below $1.3 \mathrm{~m}$ ).

138 The ALS sensors can record many echoes per pulse. In the current study, we used the three echo

139 categories classified as single, first of many, and last of many. The single and first of many echoes were

140 pooled into one dataset denoted as first echoes, and correspondingly, the single and last of many

141 echoes were pooled into a dataset denoted as last echoes. All ALS metrics were calculated separately for

142 first and last return laser echoes, resulting in a total of 44 variables. Response and predictor variables

143 were log transformed to ameliorate their nonlinear relationship. The models were selected and fit

144 independently for each cover class using generalized least squares (GLS) (Table 2). The correlation

145 structure was specified by compound symmetry, pairing the observations from the two times on the

146 same field plot. The variable selection process was semi-automated. Initially, 20 variable combinations

147 were selected using best subset method with Bayesian information criterion (BIC) and restricting the

148 maximum number of variables to five. In the next step, the models with variance inflation factor (VIF)

149 greater than five were filtered out and the best of the remaining models was selected for further

150 inspection. To allow likelihood tests in the automated selection phase, parameter fitting was done using

151 maximum likelihood (ML), and the selected model was subsequently refitted using restricted maximum

152 likelihood (REML) (Pinheiro et al. 2013; Zuur et al. 2009). 


\section{$153 \quad 2.3$ StATISTICAL METHODS}

\section{$154 \quad$ 2.3.1 Estimators}

$155 \mathrm{MA}$ and HY estimators are used to estimate mean AGB $(\mathrm{Mg} / \mathrm{ha})$ values for each time as well as the 156 change in AGB over the five year period. In the MA estimation, the ALS and the field surveys are used in 157 a two-stage sampling design, a method initially proposed by Gregoire et al. (2011) and further 158 developed by Ringvall et al. (2016) to address the dependencies between stratum-wise estimates, a 159 consequence that follow when ALS strips intersect several strata. The hybrid estimator combines 160 design-based and model-based inferences to estimate uncertainty by considering the sampling error of 161 the ALS survey as well as the model error (Ståhl et al. 2011).

162 A feature shared by both estimators is the predictive model linking the remotely sensed data to the 163 variable of interest. Let us generically define this relation as $\hat{y}=f(\widehat{\boldsymbol{\beta}}, \boldsymbol{x})$, where $\widehat{\boldsymbol{\beta}}$ is a vector of model 164 parameter estimates and $\boldsymbol{x}$ a vector of predictor variables considered error-free. Furthermore, let S1 165 denote the ALS strip sampling survey, and S2 the field plot survey. In the context of MA estimation, the 166 meaning of these are: S1 - first stage sample ( $m$ ALS strips), S2 - second stage sample ( $n$ field plots).

167 The parameter of interest in this study is mean AGB. The overall mean across all strata is estimated as:

168 (1) $\quad \hat{\mu}_{*}=\sum_{h=1}^{H} W_{h} \hat{\mu}_{*, h}$

169 where $H$ is the number of strata, $W_{h}$ is the area proportion of stratum $h$, and $\hat{\mu}_{*, h}$ is the estimated 170 mean in stratum $h$. Here $*$ stands for either MA or HY, indicating the framework. The stratum-wise mean 171 is

$172 \quad$ (2) $\quad \hat{\mu}_{*, h}=\frac{\sum_{i=1}^{m} \hat{t}_{*, i h}}{\sum_{i=1}^{m} A_{i h}}$ 
173 where $\hat{t}_{*, i h}$ and $A_{\text {ih }}$ are the total predicted AGB and the area of stratum $h$ in ALS strip $i$. These totals are 174 estimated differently in MA and HY frameworks:

175

176

(3) $\quad \hat{t}_{M A, i h}=\sum_{k=1}^{N_{i h}} \hat{y}_{k h}+\frac{N_{i h}}{n_{i h}} \sum_{k=1}^{n_{i h}}\left(y_{k h}-\hat{y}_{k h}\right)$

(4) $\quad \hat{t}_{H Y, i h}=\sum_{k=1}^{N_{i h}} \hat{y}_{k h}$

177 where $n_{i h}$ is the number of field plots in strip $i$, stratum $h, N_{i h}$ the total number of cells in strip $i$,

178 stratum $h, \hat{y}_{k h}$ are synthetic predictions of AGB via a stratum specific model $\left.f_{h}\left(\widehat{\boldsymbol{\beta}}_{\boldsymbol{h}}, \boldsymbol{x}\right)\right)$, and $y_{k h}$ are the

179 values from the field survey ( $k$ indexes cells), considered error-free. The second term in the MA

180 estimator (Eq. 3) is a bias correction based on the second stage sample.

181 The variance estimators of these estimators are:

182

183

(5) $\quad \widehat{\operatorname{Var}}\left(\hat{\mu}_{M A}\right)=\boldsymbol{W}^{\boldsymbol{T}} \widehat{\boldsymbol{C o v}}_{S 1(M A)} \boldsymbol{W}+\boldsymbol{W}^{\boldsymbol{T}} \widehat{\boldsymbol{C o v}}_{S 2} \boldsymbol{W}$

(6) $\quad \widehat{\operatorname{Var}}\left(\hat{\mu}_{H Y}\right)=\boldsymbol{W}^{T} \widehat{\boldsymbol{C o v}}_{S 1(H Y)} \boldsymbol{W}+\boldsymbol{W}^{\boldsymbol{T}} \widehat{\boldsymbol{\operatorname { C o v }}}{ }_{M} \boldsymbol{W}$

184

185

(7) $\quad \widehat{\operatorname{Var}}\left(\hat{\mu}_{M A, h}\right)=\widehat{\boldsymbol{C o v}}_{S 1(M A)}[h, h]+\widehat{\boldsymbol{C o v}}_{S 2}[h, h]=\widehat{\operatorname{Var}}_{S 1(M A)}\left(\hat{\mu}_{M A, h}\right)+\widehat{\operatorname{Var}}_{S 2}\left(\hat{\mu}_{M A, h}\right)$

(8) $\quad \widehat{\operatorname{Var}}\left(\hat{\mu}_{H Y, h}\right)=\widehat{\boldsymbol{C o v}}_{S 1(H Y)}[h, h]+\widehat{\boldsymbol{C o v}}_{M}[h, h]=\widehat{\operatorname{Var}}_{S 1(H Y)}\left(\hat{\mu}_{H Y, h}\right)+\widehat{\operatorname{Var}}_{M}\left(\hat{\mu}_{H Y, h}\right)$

187 covariance matrices:

188

(9) $\quad \widehat{\boldsymbol{C o v}}_{S 1(*)}\left[h, h^{\prime}\right]=\frac{1}{\bar{A}_{h} \bar{A}_{h^{\prime}}}\left(\frac{1}{m}-\frac{1}{M}\right) \frac{\sum_{i=1}^{m}\left(\left(\hat{t}_{*, i h}-\widehat{\mu}_{*, h} A_{i h}\right)\left(\hat{t}_{*, i h^{\prime}}-\widehat{\mu}_{*, h^{\prime}} A_{i h^{\prime}}\right)\right)}{m-1}$

189

(10) $\widehat{\boldsymbol{C o v}}_{S 2}\left[h, h^{\prime}\right]=\left\{\begin{array}{c}0, h \neq h^{\prime} \\ \frac{1}{m M \bar{A}_{h}^{2}} \sum_{i=1}^{m} \widehat{\operatorname{Var}}\left(\hat{t}_{M A, i h}\right), h=h^{\prime}\end{array}\right.$

190

(11) $\widehat{\boldsymbol{C o v}_{M}}\left[h, h^{\prime}\right]=\frac{1}{\bar{A}_{h} \bar{A}_{h^{\prime}}} \hat{\overline{\boldsymbol{t}}}_{h}^{\prime T} \widehat{\boldsymbol{C o v}}_{\boldsymbol{\beta}, h, h^{\prime}}{\hat{\hat{\boldsymbol{t}}_{h^{\prime}}^{\prime}}}^{\prime}$ 
191 where $h$ and $h^{\prime}$ index two strata, $\bar{A}_{h}$ is the mean area of stratum $h$ across the $m$ ALS strips crossing the

192 stratum, and $\widehat{\operatorname{Var}}\left(\hat{t}_{M A, i h}\right)$ is the within-strip variance of total AGB in stratum $h$ (Ringvall et al. 2016, eq.

193 16). In Eq. 11, $\hat{\overline{\boldsymbol{t}}}_{h}^{\prime}=\frac{1}{m} \sum_{i=1}^{m} \hat{\boldsymbol{t}}_{h}^{\prime}$ and $\hat{\boldsymbol{t}}_{h}^{\prime}=\sum_{k=1}^{N_{i h}} \boldsymbol{\nabla} f_{h}\left(\widehat{\boldsymbol{\beta}}_{\boldsymbol{h}}, \boldsymbol{x}_{\boldsymbol{h} \boldsymbol{k}}\right)$. Since $\boldsymbol{\nabla} f_{h}$ is the gradient of $f_{h}$ with respect

194 to $\widehat{\boldsymbol{\beta}}_{h}$ parameters, $\hat{\overline{\boldsymbol{t}}}_{h}^{\prime}$ is a vector of the same dimension as $\widehat{\boldsymbol{\beta}}_{\boldsymbol{h}}$ (i.e., equal to the number of parameters

195 in the model for stratum $h$ ). If $\widehat{\boldsymbol{\beta}}_{h}$ and $\widehat{\boldsymbol{\beta}}_{h^{\prime}}$ have dimensions $P_{h}$ and $P_{h^{\prime}}$, then $\widehat{\boldsymbol{C o v}} \boldsymbol{\beta}_{\boldsymbol{\beta}, h, h^{\prime}}$ is a $P_{h} \times P_{h^{\prime}}$

196 covariance matrix estimating the uncertainty in model parameters $\widehat{\boldsymbol{\beta}}_{h}$ and $\widehat{\boldsymbol{\beta}}_{h^{\prime}}$.

197 First, note that these variances (Eq. 5-8) add two components that correspond to independent sources

198 of uncertainty. The first component in both MA and HY frameworks is the sampling variance of the strip

199 sampling survey $(S 1)$, caused by variation between estimated strip means $\left(\widehat{\boldsymbol{C o v}}{ }_{S 1(*)}\right)$. The second

200 variance component has different interpretations for MA and HY frameworks. In the case of MA, the

201 second component cumulates the variances of estimated means within each strip. These variances are

202 estimated via the residuals calculated for plots that belong to particular strip and stratum. As $S 2$ is

203 assumed to be independently conducted in each stratum, $\widehat{\boldsymbol{C O}}_{S 2}$ is a diagonal matrix. In the HY

204 framework, the second component $\left(\widehat{\boldsymbol{C o v}}{ }_{M}\right)$ is the variance attributed to uncertainty in the model

205 parameters. The $\widehat{\boldsymbol{C o v}}$ Matrix depends on the correspondence between prediction models and the

206 strata (see section 2.3.2)

207 In this study, we adopted the indirect change estimation, a method that estimates change by taking the

208 difference between single-time biomass estimates: $\hat{\mu}_{(\Delta)}=\hat{\mu}_{(2006)}-\hat{\mu}_{(2011)}$. The other alternative is to

209 estimate change directly via a "change model" (see McRoberts et al. (2015) for a comparison of the two

210 methods). Opting for the former method was on the one hand constrained by the few plots available in

211 some strata, resulting in poor change models, and on the other hand motivated by the advantage of

212 being able to report single-time AGB values, as well as change that is consistent with them (i.e., with

213 direct change estimation, $\left.\hat{\mu}_{(\Delta)} \neq \hat{\mu}_{(2006)}-\hat{\mu}_{(2011)}\right)$. 
214 Indirect estimates of change for the $i$-th ALS strip is

215

(12) $\quad \hat{t}_{(\Delta), i h}=\hat{t}_{(2006), i h}-\hat{t}_{(2011), i h}$

216 and at the stratum level

$217 \quad(13) \quad \hat{\boldsymbol{t}}_{(\Delta) h}^{\prime}=\hat{\boldsymbol{t}}_{(2006) h}^{\prime}-\hat{\boldsymbol{t}}_{(2011) h}^{\prime}$

218 These relations (Eq. 12, 13) hold only when these totals are calculated on perfectly overlapped ALS strip

219 samples, which is the case in this study.

220 To assess the advantage of using the ALS sample to support the field survey, the precisions of MA and

221 HY estimators are compared to that obtained by direct estimation using only the field sample. Here we

222 use the Horvitz-Thompson (HT) estimator following stratified random sampling (Särndal et al. 1992). Let

$223 \hat{\mu}_{H T}$ denote the estimated mean AGB and $\widehat{\operatorname{Var}}\left(\hat{\mu}_{H T}\right)$ the estimated variance. The relative efficiency of

224 MA and HY estimators with respect to the HT estimator is calculated as the ratio of variances: $\frac{\sqrt[V a r]{ }\left(\widehat{\mu}_{H T}\right)}{\sqrt{\operatorname{ar}}\left(\widehat{\mu}_{M A}\right)^{\prime}}$

225 and $\frac{\widehat{\operatorname{Var}}\left(\widehat{\mu}_{H T}\right)}{\widehat{\operatorname{Var}}\left(\widehat{\mu}_{H Y}\right)}$.

\section{$226 \quad$ 2.3.2 Post-stratification}

227 In this study, two different stratification schemes were tried: by cover class only, and by cover class and 228 change class. The first scheme is a simple one and has been used before. With stratification by cover 229 class, there is a one to one correspondence between the five strata and the models that predict AGB 230 values in these strata (see Table 2). In this case, the matrix $\widehat{\boldsymbol{C o v}}{\boldsymbol{\beta}, h, h^{\prime}}=\mathbf{0}$ when $h \neq h^{\prime}$ due to the use of 231 independent models in each stratum, and $\widehat{\boldsymbol{C o v}} v_{M}$ is a $5 \times 5$ diagonal matrix. The stratification by cover 232 class and change class is a nested stratification, in the sense that each area unit (or grid cell) belongs to a 233 cover class as well as a change class. It is a nested stratification, as the change class may break down 234 each cover class, and conversely, each change class can be further divided into cover classes. This means 
235 that the effective number of strata is expanded to 20 (five cover classes $x$ four change classes). With this

236 stratification scheme, $\widehat{\boldsymbol{C o v}}_{M}$ is a $20 \times 20$ matrix with a block diagonal structure (4x4 blocks). Here,

$237 \widehat{\boldsymbol{C o v}}{\widehat{\boldsymbol{\beta}, h, h^{\prime}}}=\mathbf{0}$ whenever $h$ and $h^{\prime}$ come from different cover classes. For reporting purposes, following

238 estimation, the nested strata may be collapsed by either cover class or change class. In this study, we

239 use this stratification scheme only with the HY estimation. Having many strata relative to the size of the

$240 S 2$ sample has a detrimental effect on estimating $\widehat{\boldsymbol{C o v}} v_{S 2}$ as a large of number of ALS strip-strata

241 combinations would not overlap any field plots. With the nested stratification scheme, there are 480

$242(24 \times 20)$ strip-strata combinations and only 316 field plots. Both cover classes and change classes are

243 assumed to be known without error.

\section{$244 \quad$ 2.3.3 Parametric bootstrapping}

245 An alternative method to estimate $\widehat{\boldsymbol{C o v}_{M}}$ is via parametric bootstrapping, by sampling from the 246 multivariate distribution of the estimated model coefficients. With post-stratification by cover class we 247 generated $B=1000$ bootstrap samples corresponding to the same number of sets of model coefficients $248\left(\widehat{\boldsymbol{\beta}}_{h}\right)$ in each stratum. For each set of model coefficients, new AGB predictions are calculated along the

249 ALS strips, and $\hat{\mu}_{H Y, h}$ is re-estimated. $\widehat{\boldsymbol{C o v}}_{M(\text { boot })}$ is then calculated as the variance-covariance matrix of 250 the resulting $H \times B$ mean AGB estimates $\left(\hat{\mu}_{H Y, h}\right)$. The rationale here is that since the model coefficients 251 are the only values being changed in the bootstrap sample, $\widehat{\boldsymbol{C o}} \boldsymbol{v}_{M(b o o t)}$ will isolate the model error 252 component of the HY estimator and may be compared to analytically derived $\widehat{\boldsymbol{C o v}}{ }_{M}$. It is expected that $253 \widehat{\boldsymbol{C o v}}$ (boot) matrix will converge to $\widehat{\boldsymbol{C o v}}_{M}$ as the bootstrap sample size increases. As a measure of 254 convergence, we use the mean absolute difference (MAD) between corresponding elements of $255 \widehat{\boldsymbol{C o v}}_{M(\text { boot })}$ and $\widehat{\boldsymbol{C o v}}_{M}$ matrices. 


\section{RESULTS AND DISCUSSION}

257

258

\subsection{StRATification BY COVER TYPE}

The results of MA estimation are presented in Table 4, HY estimation in Table 5, and direct estimation using field measurements only in Table 6 . The precision of the estimates is reported in terms of standard error (SE) (i.e. square root of the estimated variance). In general, the results indicate an increase in mean AGB over the 5-year period. Among the cover classes, the young forest stratum seemed to have the largest net gain in biomass, a result indicated by all three estimation methods and explained by the otherwise expected high growth rate in a young forest.

For single-time estimates, MA was in general more precise than HY (Table 3). One observation concerning MA estimation is that the within strip variance of mean AGB, which reflects the $\widehat{\boldsymbol{C o v}}$ S2 matrix, had a minor contribution to the overall variance: $2.5 \%$ for across strata estimates in both 2006 and 2011 , and between $0.4 \%$ and $9.5 \%$ for individual strata (Table 4). We identified several potential factors that are expected to affect $\widehat{\boldsymbol{C o v}}_{S 2}$ estimation. First, the lack of field plots in each ALS strip and stratum underestimates the second stage variance. This happens because $\widehat{\boldsymbol{C o v}} v_{S 2}$ cumulates the estimated within strip variances $\widehat{\operatorname{Var}}\left(\hat{t}_{M A, i h}\right)$ (Eq. 10), which in the absence of field plots cannot be estimated, and are instead assigned a value of 0 . In our case, there were 120 ALS strip-stratum combinations (i.e., 24 ALS strips $x 5$ strata), 17 of which had either none or only one field plot. By contrast, ignoring an expected negative covariance between strata in $\widehat{\boldsymbol{C o v}}$ s2 results in overestimation (Gregoire et al. 2016). Ringvall et al. (2016) used simulations to evaluate this overestimation at around $6 \%$ of the standard error. Finally, ignoring the systematic sampling design is expected to inflate the apparent variance of the estimators. This concerns both the first stage $\left(\widehat{\boldsymbol{C o v}}_{S 1(*)}\right)$ and the second stage sampling $\left(\widehat{\boldsymbol{C o v}}_{S 2}\right)$, so that the MA estimator will likely be more affected than the HY estimator. In the HY 
278 estimation, the model error $\widehat{\boldsymbol{C o v}}_{M}$ had a substantial contribution to the total variance (Table 5). It

279 accounted for $31.5 \%$ (2006) and $40.8 \%$ (2011) of the variance for overall across strata estimates, and

280 ranged between $20.1 \%$ and $77.3 \%$ for individual strata (both times).

281 Even though the estimated precision of the single-time ALS-aided estimates did not always exceed that

282 of direct estimates, for change estimation both MA and HY estimators outperformed the direct

283 estimation (Table 3). While the MA estimator seems more precise than HY in estimating overall across

284 strata change (Table 3, last row, last column block), the stratum-wise change is substantially more

285 precisely estimated by the HY estimator. The latter observation regarding stratum-wise estimates is in

286 accord with Ene et al. (2017) who tested similar MA and HY estimators without stratification. There are

287 several factors that concur to this result. First, in HY estimation, the strip post-stratum AGB values are

288 synthetic, unadjusted by the field sample, and consistently predicted by the same model on both times.

289 The synthetic predictions at the strip level are highly correlated between 2006 and 2011, in contrast to

290 the bias correction terms, which are less well correlated. For instance, the Pearson correlation

291 coefficient between $\hat{t}_{(2006) H Y, i h}$ and $\hat{t}_{(2011) H Y, i h}$ ranged from 0.972 to 0.997 for the five cover classes,

292 while for the corresponding bias correction terms (i.e., second term in Eq. 3) the correlation coefficients

293 were between 0.574 and 0.848 . This has an asymmetric effect in the sampling error $(S 1)$ of MA and HY

294 change estimators, since the bias correction term introduces more variation in the difference between

295 single-time estimates at the strip level. Another aspect is that, compared to single-time estimation,

296 when estimating change, the model error contributed less to the total variance (Table 5). The only

297 instance with an increase in model error contribution for change is the low productive forest stratum.

298 Here the inversed tendency owes to an unusually high sampling variance $(S 1)$ for the single-time

299 estimates, a component that cancelled out for change, allowing a larger proportion for the model error

300 component. 


\section{1 \\ 3.2 NeSted POST-STRATIFICATION BY COVER CLASS AND CHANGE CLASS}

302 Figure 2 illustrates the cover classes, change classes, and AGB change along a strip segment. In general,

303 in terms of precision, the HY estimation with nested post-stratification, was slightly less precise

304 compared to HY estimation with post-stratification by cover class only. When collapsing the nested post-

305 stratified estimates by cover class, a slight increase in precision or similar precision was noticed for the

306 single-time estimates by cover class (Table 3). This is due to a reduction of sampling error because of

307 each cover class being further broken down by change classes. The effect, however, is small as the

308 change class has greatly unbalanced proportions, unchanged forest being dominant in most cover

309 classes (see "stratum size" column in Table 7). A notable exception is the non-productive/non-forest

310 cover class, where the unchanged forest and unchanged non-forest change classes have relatively

311 balanced proportions. Here indeed, the improvement is visible with estimated standard error decreasing

312 from around $2.24 \mathrm{Mg} / \mathrm{ha}$ (2006) and $2.26 \mathrm{Mg} / \mathrm{ha}$ (2011) (Table 5) to $1.76 \mathrm{Mg} / \mathrm{ha}$ (2006) and $1.74 \mathrm{Mg} / \mathrm{ha}$

313 (2011) (Table 7, $5^{\text {th }}$ row block), paralleled by an increase in model error contribution from 58.8\% (2006

314 and 2011) (Table 5) to $86.5 \%$ (2006) and 90.2\% (2011) (Table 7, $5^{\text {th }}$ row block). Low productive forest

315 also had a noteworthy unchanged non forest proportion (8.2\%) with some impact on single-time HY

316 estimation precision: SE decreased from 7.51 Mg/ha (2006) and 7.57 Mg/ha (2011) (Table 5) to 6.69

$317 \mathrm{Mg} / \mathrm{ha}(2006)$ and $6.72 \mathrm{Mg} / \mathrm{ha}(2011)$ (Table 7, $5^{\text {th }}$ row block) whereas the model error contribution

318 increased from $20.1 \%(2006)$ and $23.2 \%(2011)$ (Table 5) to $25 \%(2006)$ and $29.5 \%(2011)\left(\right.$ Table $7,5^{\text {th }}$

319 row block). As earlier asserted, the increase in model error contribution did not coincide with an

320 increase in model error, which remained largely constant, but rather a decrease in sampling error (S1).

321 While the nested post-stratification did not help to increase the estimation precision for overall single-

322 time or change estimates, this approach retains its merits with respect to detailed reporting for change.

323 Collapsing the post-strata by change class (Table 7, last row block), gives an insight on the contribution

324 of different change classes on the overall change balance. Clear felling affected around $1.6 \%$ of the study 
325

326

327

328

329

330

331

332

333

334

335

336

337

338

339

340

341

342

343

344

345

346

347

area where an average of $87.3 \mathrm{Mg} / \mathrm{ha}(\mathrm{SE}=4.53 \mathrm{Mg} / \mathrm{ha}$ ) was lost. This means that for the entire study area clear felling contributed a negative balance of $1.34 \mathrm{Mg} / \mathrm{ha}(\mathrm{SE}=0.069 \mathrm{Mg} / \mathrm{ha})$. Regeneration, that covered $1.8 \%$ of the study area, had a net contribution of $0.17 \mathrm{Mg} / \mathrm{ha}(\mathrm{SE}=0.03 \mathrm{Mg} / \mathrm{ha}$ ). Finally, the net forest growth in the unchanged forest post-stratum, covered $84.5 \%$ of the study area, and contributed an estimated positive balance of $4.35 \mathrm{Mg} / \mathrm{ha}(\mathrm{SE}=0.91 \mathrm{Mg} / \mathrm{ha})$. Nested post-stratification revealed where a certain change class occurred preponderantly. For instance, total biomass lost to clear felling in each cover class might be of interest. To this end, the mean AGB values in the second row block in Table 7 can be transformed to totals: $146324 \mathrm{Mg}(\mathrm{SE}=30835 \mathrm{Mg})$ in non-productive/non forest, $284548 \mathrm{Mg}$ $(\mathrm{SE}=36238 \mathrm{Mg})$ in young forest, $38192 \mathrm{Mg}(\mathrm{SE}=11842 \mathrm{Mg})$ in low productive forest, $257316 \mathrm{Mg}(\mathrm{SE}=$ $14005 \mathrm{Mg}$ ) in medium productive forest, and $582282 \mathrm{Mg}(\mathrm{SE}=28877 \mathrm{Mg}$ ) in high productive forest.

\subsection{Parametric bootstrap simulation}

After 1000 bootstrap samples, the $\widehat{\boldsymbol{C o v}} \boldsymbol{v}_{\boldsymbol{M} \text { (boot) }}$ converged to the analytically derived $\widehat{\boldsymbol{C o v}} \boldsymbol{M}$ (Fig. 3, left column). Accordingly, the SE of the mean AGB (2006, 2011, and change), that was calculated based on $\widehat{\boldsymbol{C o}} \boldsymbol{v}_{\boldsymbol{M}(\boldsymbol{b o o t})}$, converged to its analytical counterpart (i.e., those in Table 6, calculated with $\widehat{\boldsymbol{C o}} \boldsymbol{v}_{\boldsymbol{M}}$ ) (Fig. 3, right column).

The role of demonstrating this alternative estimation method was twofold. First, it is a way to validate the theoretical HY estimators. In fact, we can see it as mutual validation especially in post-stratified twostage change estimation, which is not yet established in literature. Second, parametric bootstrapping is a viable alternative to isolate the model error effect when the analytical estimation becomes too complex (i.e., due to sampling design; multistage, post-stratification, etc.). One instance where this alternative simulative approach may attain its full potential is in situations that involve several modeling steps where error propagation must be accounted for. In fact, even in this study we assumed that the AGB in the NFI plots is known without error, whereas it was predicted using allometric models. Similarly, we 
assumed the post-strata to be determined without error, whereas they are typically predicted using logistic models (e.g., Næsset et al. 2013a) or other classification methods that are not exempt from errors. Given that the error structures of all models involved are properly estimated, parametric bootstrapping has the potential to integrate their effect and provide a reliable estimate of the overall

352 variance due to the errors in all modeling steps. Investigating this would be an interesting direction for

353 further research. It may worth mentioning that, when large scale wall-to-wall mapping and estimation of 354 change is of interest, the estimation methods described in this study are still applicable as the first stage 355 (MA) / phase $(\mathrm{HY})$ variance $\left(\widehat{\boldsymbol{C o v}}_{S 1}\right)$ vanishes. Besides, it is also possible to combine the non-exhaustive 356 ALS sample with inexpensive wall-to-wall auxiliaries. Here most opportunities lie within the model based

357 inference framework, as it enables for errors to be estimated at the pixel level. For instance, a

358 hierarchical, model based estimation approach using three sources of data and two modeling steps

359 proposed by Saarela et al. (2016) can be also applied for change estimation. Here, parametric

360 bootstrapping would be an excellent approach to error estimation, as it can ease the error propagation, 361 given the multiple modeling steps.

\section{CONCLUSIONS}

363 Model-assisted and hybrid estimators were demonstrated and compared in a large area survey with the 364 objective to estimate the change in above ground biomass over a 5-year period. Several conclusions can 365 be drawn from this study:

1. The potential to increase the precision of forest parameter estimation for single-time estimates using

367 MA and HY estimators with ALS strip sampling has been demonstrated before (Ene et al. 2013; Gregoire 368 et al. 2011; Ståhl et al. 2011). Here we found that for change estimation the increase in precision was even more pronounced. 
370 2. The efficiency of MA and HY estimators varies with the type of parameter estimated (i.e., single-time

371 versus change or stratum-wise versus overall across-strata), thus comparing their performance in

372 absolute terms is inconclusive, and may depend on the study area as well. Here, MA seems to be more

373 precise in overall across-strata single-time and change estimation as well as stratum-wise single-time

374 estimation, and $\mathrm{HY}$ is more precise in estimating stratum-wise change.

375 3. Parametric bootstrapping is a reliable alternative to analytical estimation of the model-error

376 component.

377 4. A nested stratification scheme, by cover class and change class, enables detailed change reporting, 378 and facilitates decision making. In addition, it has the potential to increase the estimation precision 379 given a balanced presence of more change classes within a cover class.

\section{REFERENCES}

381 Andersen, H.-E., Strunk, J., and Temesgen, H. 2011. Using Airborne Light Detection and Ranging as a

382 Sampling Tool for Estimating Forest Biomass Resources in the Upper Tanana Valley of Interior Alaska.

383 Western Journal of Applied Forestry 26(4): 157-164.

384 Bollandsås, O.M., Gregoire, T.G., Næsset, E., and Øyen, B.-h. 2013. Detection of biomass change in a $385 \quad$ Norwegian mountain forest area using small footprint airborne laser scanner data. Statistical

386 Methods \& Applications 22(1): 113-129. doi: 10.3097/LO.200701.

387 Corona, P., Fattorini, L., Franceschi, S., Scrinzi, G., and Torresan, C. 2014. Estimation of standing wood 388 volume in forest compartments by exploiting airborne laser scanning information: model-based, 389 design-based, and hybrid perspectives. Canadian Journal of Forest Research 44(11): 1303-1311. doi:

$390 \quad 10.1139 /$ cjfr-2014-0203. 
391 Ene, L.T., Næsset, E., Gobakken, T., Bollandsås, O.M., Mauya, E.W., and Zahabu, E. 2017. Large-scale 392 estimation of change in aboveground biomass in miombo woodlands using airborne laser scanning 393 and national forest inventory data. Remote Sensing of Environment 188: 106-117.

394 Ene, L.T., Næsset, E., Gobakken, T., Gregoire, T.G., Ståhl, G., and Holm, S. 2013. A simulation approach 395 for accuracy assessment of two-phase post-stratified estimation in large-area LiDAR biomass surveys. 396 Remote Sensing of Environment 133(0): 210-224.

397 Gobakken, T., Næsset, E., Nelson, R., Bollandsas, O.M., Gregoire, T.G., Stahl, G., Holm, S., Orka, H.O., and 398 Astrup, R. 2012. Estimating biomass in Hedmark County, Norway using national forest inventory field 399 plots and airborne laser scanning. Remote Sensing of Environment 123: 443-456. doi:

$400 \quad$ 10.1016/j.rse.2012.01.025.

401 Gregoire, T.G. 1998. Design-based and model-based inference in survey sampling: appreciating the 402 difference. Canadian Journal of Forest Research 28(10): 1429-1447. doi: 10.1139/x98-166.

403 Gregoire, T.G., Ringvall, A.H., Ståhl, G., and Næsset, E. 2016. Conditioning post-stratified inference 404 following two-stage, equal-probability sampling. Environmental and Ecological Statistics 23(1): 141405 154. doi: 10.1007/s10651-015-0332-9.

406 Gregoire, T.G., Ståhl, G., Næsset, E., Gobakken, T., Nelson, R., and Holm, S. 2011. Model-assisted 407 estimation of biomass in a LiDAR sample survey in Hedmark County, Norway. Canadian Journal of $408 \quad$ Forest Research 41(1): 83-95. doi: 10.1139/X10-195.

409 IPCC. 2006. Guidelines for National Greenhouse Gas Inventories. Institute for Global Environmental $410 \quad$ Strategies, Japan.

411 Magnussen, S., Næsset, E., and Gobakken, T. 2015. LiDAR-supported estimation of change in forest 412 biomass with time-invariant regression models. Canadian Journal of Forest Research 45(11): 1514$413 \quad$ 1523. doi: $10.1139 /$ cjfr-2015-0084. 
414

415

416

417

418

419

420

421

422

423

424

425

426

427

428

429

430

431

432

433

434

435

436

Marklund, L.G. 1988. Biomass functions for pine, spruce and birch in Sweden. Swedish University of Agricultural Sciences, Department of Forest Survey, Umeå.

McRoberts, R.E., Næsset, E., Gobakken, T., and Bollandsås, O.M. 2015. Indirect and direct estimation of forest biomass change using forest inventory and airborne laser scanning data. Remote Sensing of Environment 164: 36-42.

Næsset, E. 2005. Towards a laser-scanner based biomass monitoring system. In SNS Meeting, Forest Inventory and Planning in Nordic Countries, Sjusjøen, Norway. pp. 117-119.

Næsset, E., Bollandsås, O.M., Gobakken, T., Gregoire, T.G., and Ståhl, G. 2013a. Model-assisted estimation of change in forest biomass over an 11 year period in a sample survey supported by airborne LiDAR: A case study with post-stratification to provide "activity data". Remote Sensing of Environment 128: 299-314. doi: 10.1016/j.rse.2012.10.008.

Næsset, E., Gobakken, T., Bollandsås, O.M., Gregoire, T.G., Nelson, R., and Ståhl, G. 2013b. Comparison of precision of biomass estimates in regional field sample surveys and airborne LiDAR-assisted surveys in Hedmark County, Norway. Remote Sensing of Environment 130(0): 108 - 120.

Pan, Y., Birdsey, R.A., Fang, J., Houghton, R., Kauppi, P.E., Kurz, W.A., Phillips, O.L., Shvidenko, A., Lewis, S.L., Canadell, J.G., Ciais, P., Jackson, R.B., Pacala, S.W., McGuire, A.D., Piao, S., Rautiainen, A., Sitch, S., and Hayes, D. 2011. A Large and Persistent Carbon Sink in the World's Forests. Science 333(6045): 988-993. doi: 10.1126/science.1201609.

Pinheiro, J., Bates, D., DebRoy, S., Sarkar, D., and Team, R.C. 2013. nlme: Linear and Nonlinear Mixed Effects Models.

Ringvall, A.H., Ståhl, G., Ene, L.T., Næsset, E., Gobakken, T., and Gregoire, T.G. 2016. A poststratified ratio estimator for model-assisted biomass estimation in sample-based airborne laser scanning surveys. Canadian Journal of Forest Research 46(11): 1386-1395. doi: 10.1139/cjfr-2016-0158. 
437 Saarela, S., Grafström, A., Ståhl, G., Kangas, A., Holopainen, M., Tuominen, S., Nordkvist, K., and Hyyppä,

438 J. 2015. Model-assisted estimation of growing stock volume using different combinations of LiDAR

439 and Landsat data as auxiliary information. Remote Sensing of Environment 158: 431-440.

440 Saarela, S., Holm, S., Grafström, A., Schnell, S., Næsset, E., Gregoire, T.G., Nelson, R.F., and Ståhl, G.

4412016 . Hierarchical model-based inference for forest inventory utilizing three sources of information.

442 Annals of Forest Science 73(4): 895-910. doi: 10.1007/s13595-016-0590-1.

443 Skowronski, N.S., Clark, K.L., Gallagher, M., Birdsey, R.A., and Hom, J.L. 2014. Airborne laser scanner-

444 assisted estimation of aboveground biomass change in a temperate oak-pine forest. Remote Sensing

445 of Environment 151: 166-174. doi: 10.1016/j.rse.2013.12.015.

446 Ståhl, G., Holm, S., Gregoire, T.G., Gobakken, T., Næsset, E., and Nelson, R. 2011. Model-based inference

447 for biomass estimation in a LiDAR sample survey in Hedmark County, Norway. Canadian Journal of

$448 \quad$ Forest Research 41(1): 96-107. doi: 10.1139/X10-161.

449 Ståhl, G., Saarela, S., Schnell, S., Holm, S., Breidenbach, J., Healey, S.P., Patterson, P.L., Magnussen, S.,

450 Næsset, E., McRoberts, R.E., and Gregoire, T.G. 2016. Use of models in large-area forest surveys:

451 comparing model-assisted, model-based and hybrid estimation. Forest Ecosystems 3(1): 5. doi:

$452 \quad 10.1186 / s 40663-016-0064-9$.

453 Särndal, C.-E., Swensson, B., and Wretman, J.H.k. 1992. Model Assisted Survey Sampling. Springer-

$454 \quad$ Verlang, New York.

455 Tomppo, E., Gschwantner, T., Lawrence, M., and McRoberts, R.E. 2010. National Forest Inventories.

$456 \quad$ Springer Netherlands.

457 Zuur, A.F., leno, E.N., Walker, N.J., Saveliev, A.A., and Smith, G.M. 2009. Mixed Effects Models and

$458 \quad$ Extensions in Ecology with R. Springer. 
Table 1. ALS survey summary

\begin{tabular}{llcllc}
\hline Time & Date & ALS strips & Data vendor & Laser scanner & Pulse density $\left(\mathbf{m}^{-2}\right)$ \\
\hline 2006 & 22 July 2006 - 16 Sept. 2006 & $24^{*}$ & Blom Geomatics, Norway & Optech ALTM 3100 & 2.8 \\
2011 & 04 Aug. 2011-24 Sept. 2011 & 15 & Terratec, Norway & Leica ALS70 & $\sim 5$ \\
& 29 Aug. 2012-30 Sept. 2012 & 9 & & \\
\hline
\end{tabular}

Note: * in 2006 a total of 53 ALS strips were scanned covering the entire Hedmark County. Since the 2011-2012 acquisitions covered 24 strips, we were constrained to use only the 24 overlapping strips from 2006, as well as to limit the study area accordingly.

Table 2. Models summary

\begin{tabular}{llcc}
\hline Cover class & Model mean function & RSE (Mg/ha) & $\mathbf{n}$ \\
\hline Nonproductive/non-forest & $\ln (A G B)=\ln \left(h_{80(l)}\right)+\ln \left(d_{5(f)}\right)$ & 56 & $16 \times 2$ \\
Young forest & $\ln (A G B)=\ln \left(d_{3(f)}\right)+\ln \left(h_{\max (l)}\right)$ & 69 & $73 \times 2$ \\
Low productive forest & $\ln (A G B)=\ln \left(h_{40(l)}\right)+\ln \left(h_{90(l)}\right)+\ln \left(d_{0(f)}\right)$ & 53 & $38 \times 2$ \\
Medium productive forest & $\ln (A G B)=\ln \left(h_{50(l)}\right)+\ln \left(d_{5(f)}\right)+\ln \left(d_{0(l)}\right)$ & 51 & $62 \times 2$ \\
High productive forest & $\ln (A G B)=\ln \left(h_{40(f)}\right)+\ln \left(d_{4(l)}\right)+\ln \left(h_{\max (f)}\right)$ & 50 & $45 \times 2$ \\
\hline
\end{tabular}

Note: $h$ : height percentile, $d$ : density, $(f)$ : first echo, $(l)$ : last echo. Residual standard error (RSE) is transformed back to linear scale and scaled up to per-hectare values.

Table 3. Relative efficiencies of the estimators supported by the ALS survey with respect to the direct estimator

\begin{tabular}{l|ccc:ccc|ccr|}
\hline \multirow{2}{*}{ Cover class } & \multicolumn{3}{|c}{2006} & \multicolumn{3}{c}{2011} & \multicolumn{3}{c|}{ Change } \\
& MA & HY & HY* & MA & HY & HY* & MA & HY & HY* \\
\hline Nonproductive/Non-forest & 2.82 & 3.74 & 6.05 & 5.65 & 4.38 & 7.39 & 1.70 & 41.66 & 13.96 \\
Young forest & 3.84 & 0.71 & 0.74 & 2.93 & 0.73 & 0.74 & 1.03 & 2.63 & 1.97 \\
Low productive forest & 0.89 & 0.68 & 0.86 & 1.12 & 0.79 & 1.00 & 1.49 & 4.38 & 4.38 \\
Medium productive forest & 4.91 & 1.86 & 1.88 & 4.97 & 2.78 & 2.75 & 6.16 & 7.18 & 7.25 \\
High productive forest & 4.48 & 4.14 & 4.46 & 3.09 & 4.73 & 4.73 & 2.04 & 11.62 & 12.70 \\
All cover classes & 1.92 & 0.81 & 0.70 & 2.51 & 1.05 & 0.88 & 4.15 & 3.36 & 3.22 \\
\hline
\end{tabular}

Note: Bolded values (>1) indicate estimated variance greater than that of the direct estimator. $\mathrm{HY}^{*}$ is the hybrid estimator with stratification by both cover class and change class (collapsed by cover class).

Table 4. Model-assisted estimation results

\begin{tabular}{l|rrr|rrr|rrr|}
\hline \multirow{2}{*}{ Cover class } & \multicolumn{3}{|c}{$\mathbf{2 0 0 6}$} & \multicolumn{3}{c}{$\mathbf{2 0 1 1}$} & \multicolumn{3}{c|}{ Change } \\
& $\begin{array}{c}\text { Mean } \\
\text { (Mg/ha) }\end{array}$ & $\begin{array}{c}\text { SE } \\
\text { (Mg/ha) }\end{array}$ & $\%$ & $\begin{array}{c}\text { Mean } \\
\text { (Mg/ha) }\end{array}$ & $\begin{array}{c}\text { SE } \\
\text { (Mg/ha) }\end{array}$ & $\%$ & $\begin{array}{c}\text { Mean } \\
\text { (Mg/ha) }\end{array}$ & $\begin{array}{c}\text { SE } \\
\text { (Mg/ha) }\end{array}$ & $\%$ \\
\hline Nonproductive/Non-forest & 18.1 & 2.58 & 4.2 & 17.1 & 1.99 & 6.7 & -1.00 & 1.09 & 10.5 \\
Young forest & 54.7 & 2.22 & 4.8 & 61.1 & 2.87 & 4.0 & 6.36 & 1.44 & 7.4 \\
Low productive forest & 61.6 & 6.56 & 0.4 & 62.6 & 6.35 & 0.6 & 0.94 & 1.85 & 3.4 \\
Medium productive forest & 113.4 & 3.48 & 9.5 & 110.2 & 3.69 & 4.8 & -3.16 & 2.16 & 12.4 \\
High productive forest & 139.2 & 5.41 & 2.5 & 140.8 & 7.04 & 2.1 & 1.59 & 6.07 & 1.3 \\
All cover classes & 69.1 & 2.03 & 2.5 & 70.4 & 1.93 & 2.5 & 1.36 & 0.81 & 8.5 \\
\hline
\end{tabular}

Note: $\%$ denotes the percentage of variance due to the second stage sampling $\left(\widehat{\boldsymbol{C o v}} \boldsymbol{S 2}_{\mathbf{S}}\right)$

Table 5. Hybrid estimation results

\begin{tabular}{l|rrr|rrr|rrr|r}
\hline \multirow{2}{*}{ Cover class } & \multicolumn{3}{|c}{$\mathbf{2 0 0 6}$} & \multicolumn{3}{c|}{$\mathbf{2 0 1 1}$} & \multicolumn{3}{c|}{ Change } \\
& $\begin{array}{c}\text { Mean } \\
\text { (Mg/ha) }\end{array}$ & $\begin{array}{c}\text { SE } \\
\text { (Mg/ha) }\end{array}$ & \% & $\begin{array}{c}\text { Mean } \\
\text { (Mg/ha) }\end{array}$ & $\begin{array}{c}\text { SE } \\
\text { (Mg/ha) }\end{array}$ & $\%$ & $\begin{array}{c}\text { Mean } \\
\text { (Mg/ha) }\end{array}$ & $\begin{array}{c}\text { SE } \\
\text { (Mg/ha) }\end{array}$ & $\%$ \\
\hline Nonproductive/Non-forest & 18.9 & 2.24 & 58.8 & 19.6 & 2.26 & 58.8 & 0.77 & 0.22 & 56.1 \\
Young forest & 53.4 & 5.16 & 72.8 & 60.3 & 5.73 & 77.3 & 6.83 & 0.90 & 49.5 \\
Low productive forest & 59.6 & 7.51 & 20.1 & 65.3 & 7.57 & 23.2 & 5.63 & 1.08 & 73.3 \\
Medium productive forest & 110.2 & 5.65 & 43.8 & 109.4 & 4.94 & 53.5 & -0.83 & 2.00 & 9.4 \\
High productive forest & 135.8 & 5.63 & 64.2 & 137.8 & 5.69 & 67.6 & 1.95 & 2.54 & 21.6 \\
All cover classes & 67.6 & 3.12 & 31.5 & 70.6 & 2.99 & 40.8 & 3.05 & 0.90 & 11.0 \\
\hline
\end{tabular}

Note: $\%$ denotes the percentage of variance due to the model error $\left(\widehat{\boldsymbol{C o v}} \boldsymbol{v}_{M}\right)$ 
Table 6. Direct estimation using field data only

\begin{tabular}{l|rr|rr|rr|}
\hline \multirow{3}{*}{ Cover class } & \multicolumn{2}{|c}{$\mathbf{2 0 0 6}$} & \multicolumn{2}{c}{$\mathbf{2 0 1 1}$} & \multicolumn{2}{c}{ Change } \\
& $\begin{array}{c}\text { Mean } \\
\text { (Mg/ha) }\end{array}$ & $\begin{array}{c}\text { SE } \\
\text { (Mg/ha) }\end{array}$ & $\begin{array}{c}\text { Mean } \\
\text { (Mg/ha) }\end{array}$ & $\begin{array}{c}\text { SE } \\
\text { (Mg/ha) }\end{array}$ & $\begin{array}{c}\text { Mean } \\
(\mathbf{M g} / \mathbf{h a})\end{array}$ & $\begin{array}{c}\text { SE } \\
(\mathbf{M g} / \mathrm{ha})\end{array}$ \\
\hline Nonproductive/Non-forest & 16.4 & 4.33 & 17.9 & 4.73 & 1.52 & 1.42 \\
Young forest & 31.3 & 4.35 & 41.9 & 4.91 & 10.62 & 1.46 \\
Low productive forest & 48.6 & 6.20 & 51.4 & 6.71 & 2.76 & 2.26 \\
Medium productive forest & 111.8 & 7.71 & 119.9 & 8.23 & 8.14 & 5.36 \\
High productive forest & 129.6 & 11.45 & 135.6 & 12.37 & 6.02 & 8.66 \\
All cover classes & 58.4 & 2.81 & 64.8 & 3.06 & 6.38 & 1.65 \\
\hline
\end{tabular}

Table 7. Hybrid estimation results with nested stratification by cover class and change class.

\begin{tabular}{|c|c|c|c|c|c|c|c|c|c|c|c|}
\hline \multirow{2}{*}{ Change class } & \multirow{2}{*}{ Cover class } & \multirow{2}{*}{$\begin{array}{l}\text { Estimated } \\
\text { stratum size } \\
\left(\mathrm{km}^{2}\right)\end{array}$} & \multicolumn{3}{|c|}{2006} & \multicolumn{3}{|c|}{2011} & \multicolumn{3}{|c|}{ Change } \\
\hline & & & $\begin{array}{c}\text { Mean } \\
\text { (Mg/ha) }\end{array}$ & $\begin{array}{c}\mathrm{SE} \\
\text { (Mg/ha) }\end{array}$ & $\%$ & $\begin{array}{c}\text { Mean } \\
\text { (Mg/ha) }\end{array}$ & $\begin{array}{c}\mathrm{SE} \\
\text { (Mg/ha) }\end{array}$ & $\%$ & $\begin{array}{c}\text { Mean } \\
\text { (Mg/ha) }\end{array}$ & $\begin{array}{c}\mathrm{SE} \\
\text { (Mg/ha) }\end{array}$ & $\%$ \\
\hline \multirow{5}{*}{ Unchanged forest } & Non-forest & 878.6 & 41.9 & 3.89 & 92.5 & 43.7 & 3.94 & 92.9 & 1.83 & 0.44 & 69.3 \\
\hline & Young & 3017.9 & 55.5 & 5.31 & 73.9 & 63.7 & 6.03 & 78.0 & 8.12 & 1.02 & 56.1 \\
\hline & Low & 1125.7 & 66.3 & 7.45 & 25.2 & 72.9 & 7.49 & 29.6 & 6.61 & 1.19 & 76.5 \\
\hline & Medium & 2050.4 & 110.1 & 5.63 & 43.9 & 110.5 & 5.01 & 53.1 & 0.40 & 1.98 & 9.9 \\
\hline & High & $1176.7 !$ & 134.4 & 5.52 & 64.5 & 141.3 & 5.84 & 67.5 & 6.92 & 2.46 & 27.9 \\
\hline \multirow{5}{*}{ Clear felled } & Non-forest & 62.8 & 23.3 & 4.91 & 99.1 & & & & -23.28 & 4.91 & 99.1 \\
\hline & Young & $31.9 !$ & 89.2 & 11.36 & $58.5 !$ & & & & -89.22 & 11.36 & $58.5 !$ \\
\hline & Low & $12.4 \vdots$ & 30.8 & 9.55 & $4.7 !$ & & & & -30.75 & 9.55 & $4.7 !$ \\
\hline & Medium & $16.4 \vdots$ & 156.9 & 8.54 & $56.5 !$ & & & & -156.88 & 8.54 & $56.5 !$ \\
\hline & High & 26.3 & 221.4 & 10.98 & 75.9 & & & & -221.36 & 10.98 & $75.9 !$ \\
\hline \multirow{5}{*}{ Regeneration } & Non-forest & 63.1 & & & & 22.4 & 4.67 & 99.4 & 22.45 & 4.67 & 99.4 \\
\hline & Young & 92.4 & & & & 1.5 & 0.15 & 80.6 & 1.49 & 0.15 & 80.6 \\
\hline & Low & $16.3 !$ & & & & 1.7 & 0.23 & $94.6 !$ & 1.70 & 0.23 & 94.6 \\
\hline & Medium & $2.1 \vdots$ & & & & 11.5 & 1.95 & 26.8 & 11.55 & 1.95 & 26.8 \\
\hline & High & $2.6 !$ & & & & 7.1 & 1.15 & $27.1 \vdots$ & 7.14 & 1.15 & 27.1 \\
\hline \multirow{5}{*}{ Unchanged non-forest } & Non-forest & 1026.4 & & & & & & & & & \\
\hline & Young & 48.9 & & & & & & & & & \\
\hline & Low & 103.6 & & & & & & & & & \\
\hline & Medium & $1.9 !$ & & & & & & & & & \\
\hline & High & $1.6 !$ & & & & & & & & & \\
\hline \multirow{5}{*}{ All change classes } & Non-forest & 2030.9 & 18.9 & 1.76 & $86.5:$ & 19.6 & 1.74 & $90.2 \vdots$ & 0.77 & 0.38 & $54.4:$ \\
\hline & Young & 3191.1 & 53.4 & 5.07 & 72.8 & 60.3 & 5.71 & 77.8 & 6.83 & 1.04 & $55.6 !$ \\
\hline & Low & $1258.1 !$ & 59.6 & 6.69 & $25.0 !$ & 65.3 & 6.72 & $29.5 !$ & 5.63 & 1.08 & $75.5 !$ \\
\hline & Medium & $2070.8 \vdots$ & 110.2 & 5.62 & $43.2 !$ & 109.4 & 4.96 & $53.1 !$ & -0.83 & 1.99 & $9.5 !$ \\
\hline & High & 1207.3 & 135.8 & 5.42 & 63.6 & 137.8 & 5.69 & 67.5 & 1.95 & 2.43 & 27.4 \\
\hline Unchanged forest & \multirow{4}{*}{$\begin{array}{l}\text { All cover } \\
\text { classes }\end{array}$} & 8249.4 & 80.4 & 3.90 & 29.4 & 85.5 & 3.86 & 37.3 & 5.15 & 1.08 & 13.6 \\
\hline Clear felled & & 149.7 & 87.3 & 4.53 & 53.4 & & & & -87.30 & 4.53 & 53.4 \\
\hline Regeneration & & $176.6 !$ & & & & 9.2 & 1.67 & $99.2 !$ & 9.21 & 1.67 & $99.2 \vdots$ \\
\hline Unchanged non-forest & & 1182.5 & & & & & & & & & \\
\hline All & All & $9758.1:$ & 69.3 & 3.35 & $29.7 !$ & 72.5 & 3.27 & $37.3 !$ & 3.18 & 0.92 & $11.5 !$ \\
\hline
\end{tabular}

Note: First four row blocks (separated by dashed lines) show estimates of the 20 expanded strata (four change classes $x$ five cover classes). The $5^{\text {th }}$ and $6^{\text {th }}$ row blocks (separated by solid lines) are estimates collapsed by cover class and change class respectively. $\%$ denotes the percentage of variance due to the model error $\left(\widehat{\mathbf{C O}} v_{M}\right)$. For cover classes, a short notation is used. 
Fig. 1. Study area: southern portion of Hedmark County, Norway. The black dots are the locations of the $\mathrm{NFI}$ plots, and the white stripes are ALS flight lines.

Fig. 2. Cover classes, change classes, and AGB change predictions along an ALS strip segment.

Fig. 3. Convergence plots for the parametric bootstrap simulation. Plots on the left show the mean absolute difference (MAD) between the $H \times H$ elements of $\widehat{\boldsymbol{C o v}}_{\boldsymbol{M}(\boldsymbol{b o o t})}$ and $\widehat{\boldsymbol{C o} \boldsymbol{v}_{\boldsymbol{M}}}$ matrices. Plots on the right show the SE calculated with $\widehat{\boldsymbol{C o v}} \boldsymbol{M}_{(\boldsymbol{b o o t})}$, and the gray line is the SE calculated with $\widehat{\boldsymbol{C o v}} \boldsymbol{M}$ 


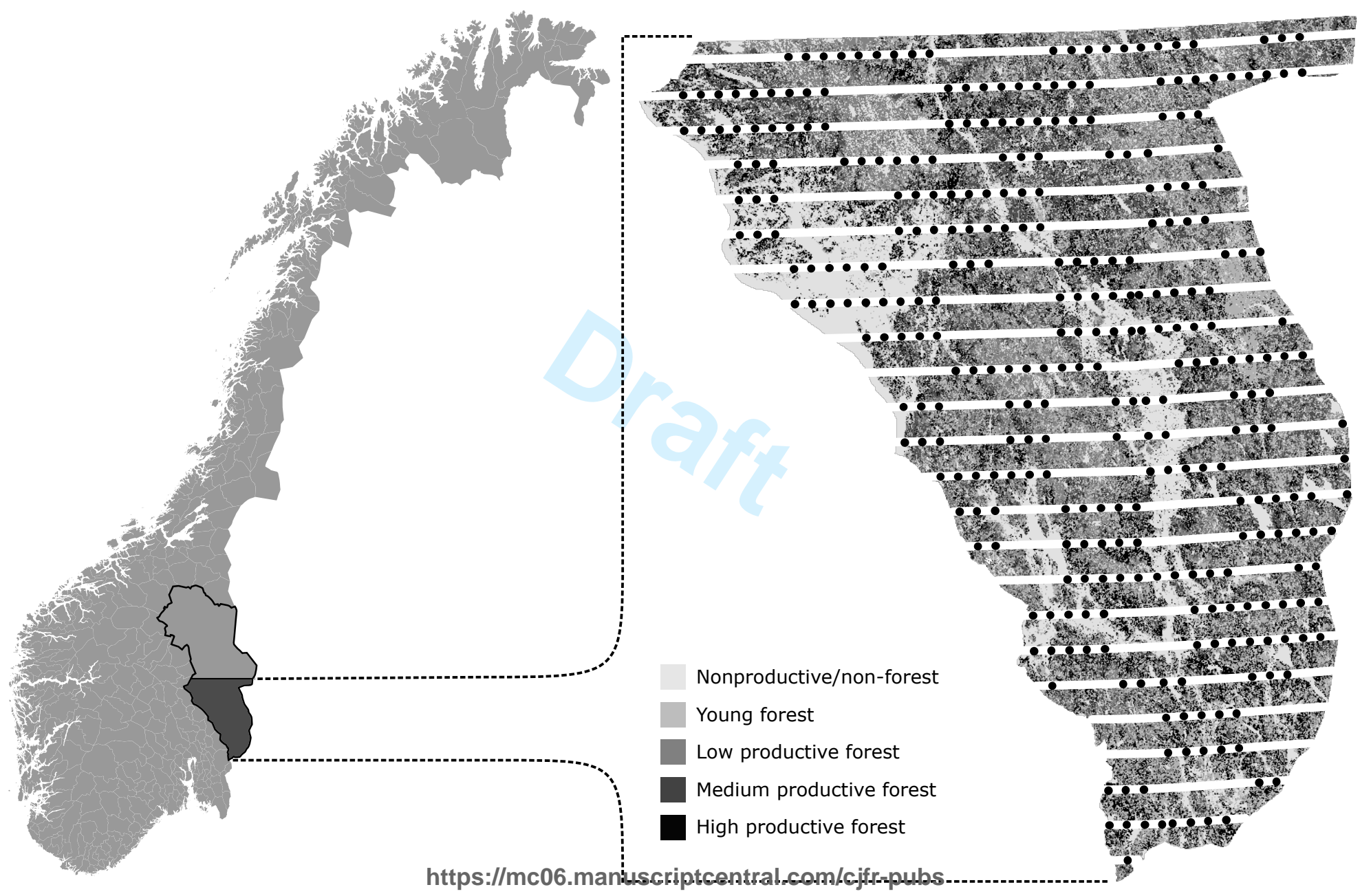


(A)

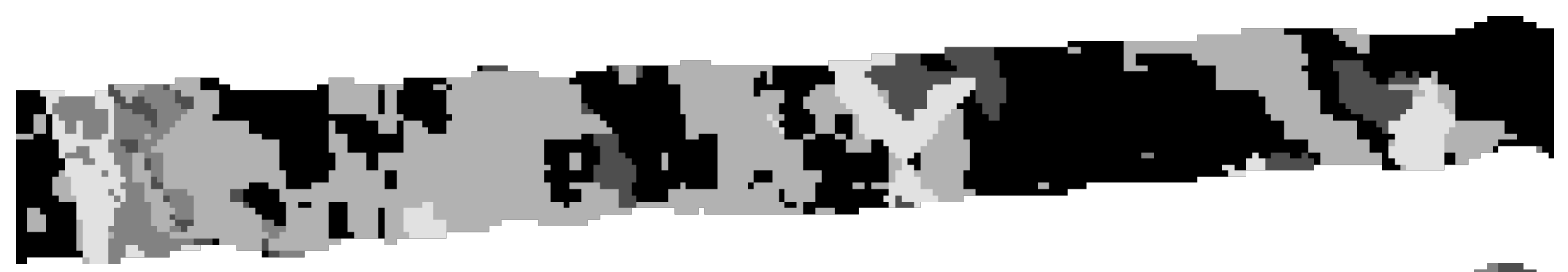

(B)

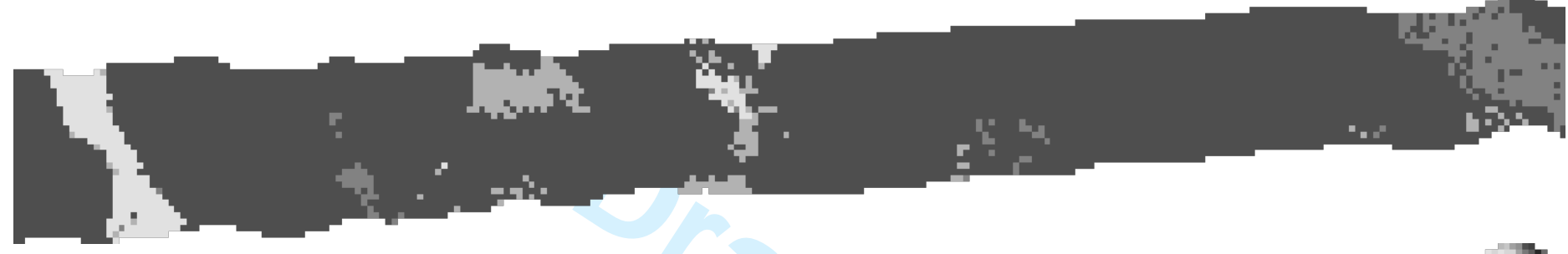

(C)

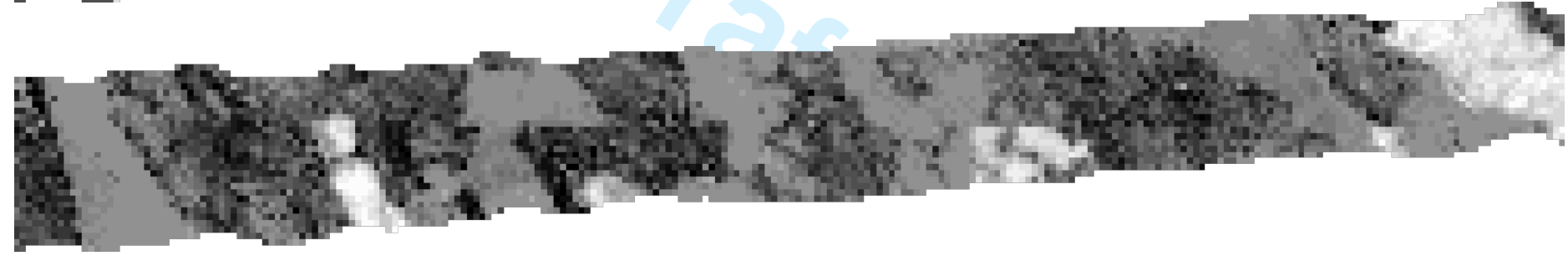

\section{(A) Cover class}

Nonproductive/non-forest

Young forest

Low productive forest

Medium productive forest

High productive forest
(B) Change class

Unchanged forest

Clear felled

Regenerated

Unchanged non-forest

https://mc06.manuscriptcentral.com/cjfr-pubs
(C) AGB change ( $\mathrm{Mg} / \mathrm{ha}$ ) $-200$ 


\section{Page 27 of 27}
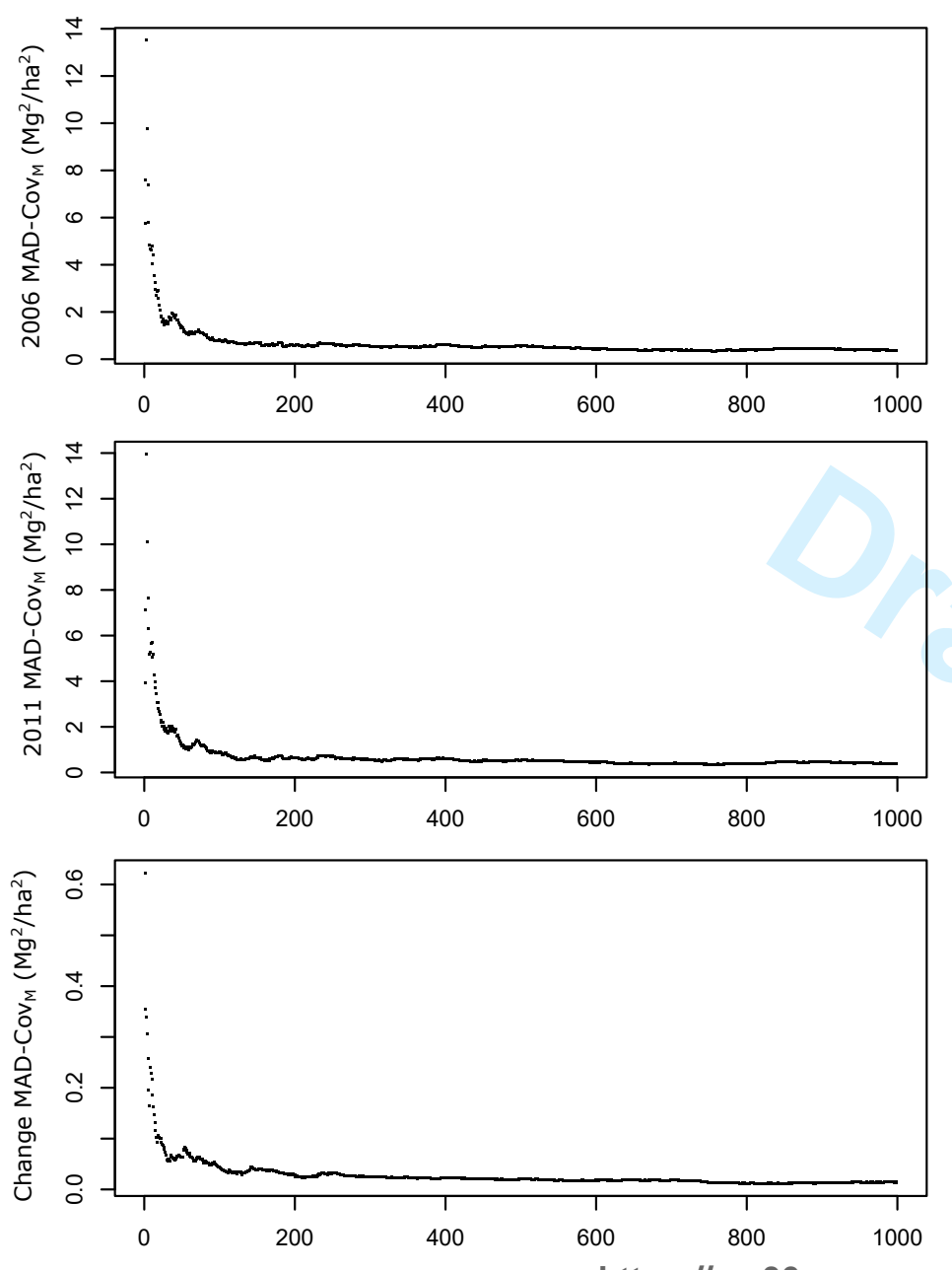

Number of bootstrap sampltps: $/ /$ mc06.manuscriptcentral.com/cjfr-pubs Number of bootstrap samples
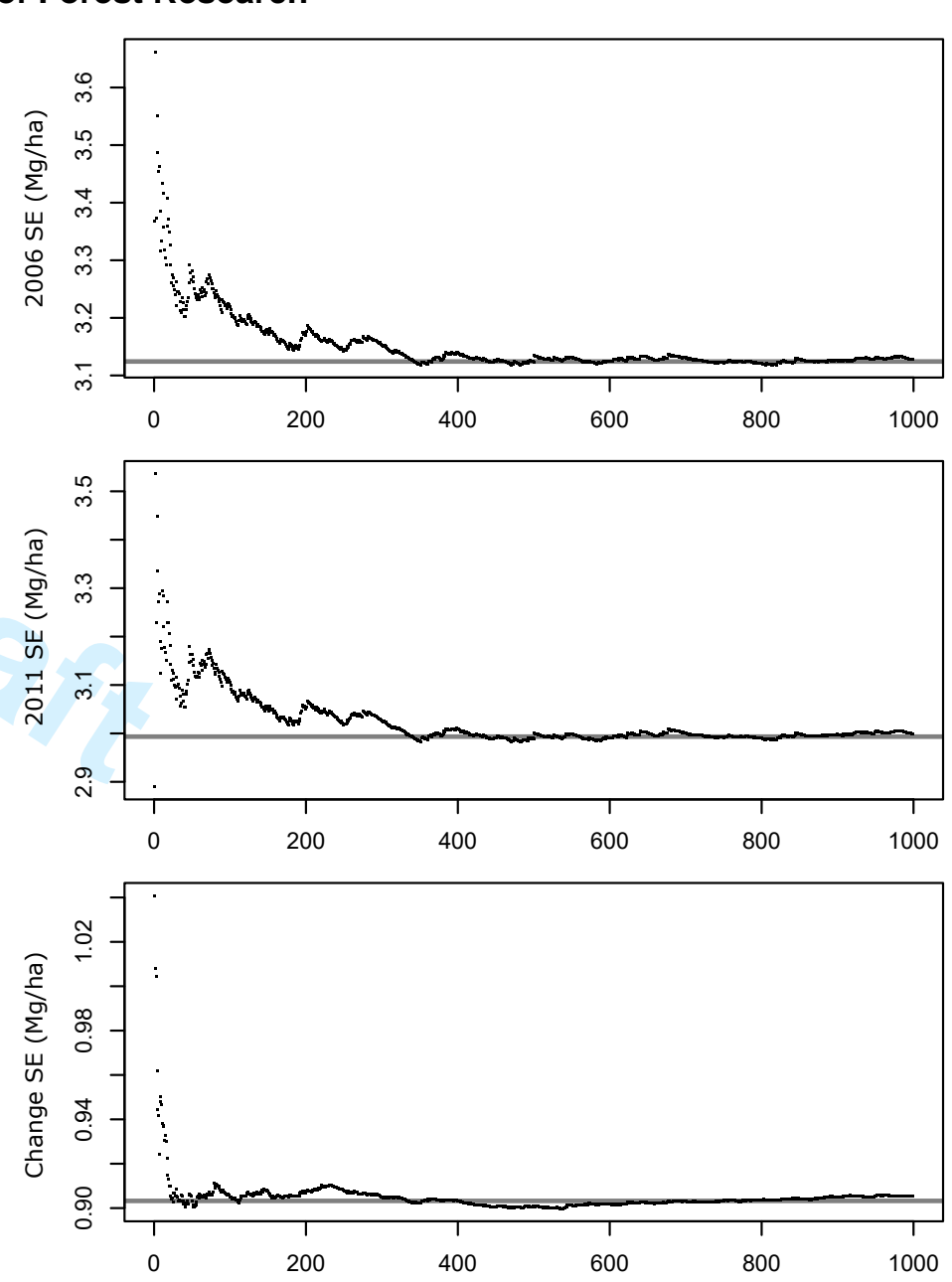